\section{Association of MBL2 variants with early preterm delivery}

\section{To the Editor:}

In a recent, interesting study, Bodamer et al. ${ }^{1}$ reported that the structural R52C and the promoter $-550 \mathrm{G}>\mathrm{C}$ variants of the MBL-2 gene are significantly associated with newborn prematurity. In particular, R52C polymorphism prevalence was increased and $-550 \mathrm{G}>\mathrm{C}$ was decreased in premature infants, supporting the possible infectious etiology of preterm delivery. Furthermore, $\mathrm{O} / \mathrm{O}$ genotype was also associated with prematurity. These MBL-2 variants may be linked to reduced amounts of MBL protein, depending on their combinations. In fact, another study ${ }^{2}$ appeared in the same period and reported that premature infants had lower serum MBL values.

In this letter, we report data concerning the study of MBL-2 variants determined by a commercially available reverse dot blot kit, (Innoplia MBL2 Assay, plus Autolipa and LIRAS software, Innogenetics, Ghent, Belgium). Eighty-nine preterm infants were subdivided by either week of gestational age $(\leq 27$ weeks or $>27$ weeks) or birth weight (1000 g as a cut-off, i.e., extremely low birth weight), representing two methods to evaluate the grade of prematurity. The results (see Table 1) showed that premature infants with gestational age $\leq 27$ weeks were significantly more likely to be carrying the $\mathrm{R} 52 \mathrm{C}$ variant compared with those $>27$ weeks $(P=0.01)$. This was also true for infants with the "O" genotype $(P=0.031)$. The $-550 \mathrm{G}>\mathrm{C}$ genotype was significantly lower in infants with gestational age $\leq 27$ weeks $(P=0.02)$. Similar results were observed when the birth weight was $\leq 1000$ grams versus $>1000$ grams (data not shown). The MBL-2 $-221 \mathrm{G}>\mathrm{C}$ variant results were similar to those of $-550 \mathrm{G}>\mathrm{C}$ as these two variants are in strong linkage disequilibrium. Infants with the $\mathrm{R} 52 \mathrm{C}$ variant were also characterized by higher median duration of continuous positive airway pressure (CPAP) values [heterozygous: 759 hours (range 3-1170 hours) versus wild type: 160 hours (range $0-1320 ; P=0.03$ by Mann-Whitney $U$ test)], higher median duration of mechanical ventilation [heterozygous: 160 hours (range 0-873) versus wild type: 61 hours [range 0-1000 hours; $P=0.03)$ ] and hospitalization days [heterozygous: 85 days (range 3-125 days) compared with wild type: 50 days (range
0-150 days; $P=0.045)]$. Duration of CPAP, mechanical ventilation, and hospitalization stay are obviously indicators of the pulmonary and clinical status of the newborns. Infants with the $\mathrm{O}$ genotype had a significantly decreased gestational age compared with those with the A genotype [O: 27 weeks (range 24-33 weeks), A: 29 weeks (range 24-36 weeks; $P=0.045$ ].

In contrast, MBL-2 $-550 \mathrm{G}>\mathrm{C}$ (and $-221 \mathrm{G}>\mathrm{C}$, data not shown) variants were both associated with higher median gestational age [homozygous + heterozygous: 29 weeks (range 24-36 weeks) versus wild type: 26 (range $24-33$ weeks; $P=$ $0.04)$ ], higher median birth weight [homozygous + heterozygous: $1050 \mathrm{~g}$ (range $460-3170 \mathrm{~g}$ ) versus wild type: $710 \mathrm{~g}$ (range 460-2790 g; $P=0.04)$ ], lower median duration of CPAP [homozygous + heterozygous: 158 hours (range 0-1320 hours) versus wild type: 558 hours (range 140-1184 hours; $P=0.01)]$, lower median number of hours of mechanical ventilation [homozygous + heterozygous: 65 hours (range 0-740 hours) versus wild type: 163 hours (range 32-502 hours; $P=0.04)$ ], and, finally, a lower median number of hospitalization days [homozygous + heterozygous: 47 days (range 0-150 days versus wild type: 92 days (range 67-109 days; $P=0.002)$ ].

The promoter $-550 \mathrm{G}>\mathrm{C}$ variant was often homozygous (40\%) and often associated with $-221 \mathrm{G}>\mathrm{C}$ variant (therefore serum MBL levels are expected to be very low), whereas R52C variant was exclusively heterozygous (14\%) and rarely $\mathrm{O} / \mathrm{O}$ (therefore the serum MBL levels are expected to be normal or slightly reduced). These data are in agreement with the work of Frakking et al., ${ }^{2}$ which reported that premature infants had MBL levels lower than those of infants born at term.

Recent studies revealing a high prevalence of variants in different populations and evolutionary observations ${ }^{3}$ support the idea that MBL-2 variants may sometimes have protective effects or the opposite in different situations. It is protective when an aggressive pathogen capable of activating MBL should be eliminated by an inflammatory complement-dependent response, whereas a dangerous effect may happen when this persistent activation leads to uncontrolled inflammatory processes.

In conclusion, our data confirm and extend the importance of knowing the MBL-2 polymorphisms, so as to be aware of the

Table 1

Distribution of two MBL2 variants $(-550 \mathrm{G}>\mathrm{C}$ and $-221 \mathrm{G}>\mathrm{C}$ ) and the $\mathrm{R} 52 \mathrm{C}$ gene or the genotype A/O in 89 preterm infants

\begin{tabular}{|c|c|c|c|c|c|c|c|c|}
\hline \multirow[b]{2}{*}{ Variants } & \multicolumn{2}{|c|}{ Promoter-550 G $>C$} & \multicolumn{2}{|c|}{ Promoter-221 G>C } & \multicolumn{2}{|c|}{ Gene R52C } & \multicolumn{2}{|c|}{ Genotype A/O } \\
\hline & $\mathrm{hm}+\mathrm{ht}$ & wt & $\mathrm{hm}+\mathrm{ht}$ & wt & ht & wt & $\mathrm{O}$ & A \\
\hline $\begin{array}{l}\text { Gestational } \\
\text { age } \leq 27 \text { wks }\end{array}$ & 34 & 7 & 9 & 32 & 10 & 31 & 23 & 18 \\
\hline $\begin{array}{l}\text { Gestational } \\
\quad \text { age }>27 \text { wks }\end{array}$ & 47 & 1 & 21 & 27 & 2 & 46 & 15 & 33 \\
\hline$P^{a}=$ & \multicolumn{2}{|c|}{$\begin{array}{c}0.022 \\
\mathrm{OR}=0.10, \mathrm{CI}=0.02-0.69\end{array}$} & \multicolumn{2}{|c|}{$\begin{array}{c}0.043 \\
\mathrm{OR}=0.36, \mathrm{CI}=0.14-0.91\end{array}$} & \multicolumn{2}{|c|}{$\begin{array}{c}0.010 \\
\mathrm{OR}=7.42, \mathrm{CI}=1.69-32.0\end{array}$} & \multicolumn{2}{|c|}{$\begin{array}{c}0.031 \\
\mathrm{OR}=2.81, \mathrm{CI}=1.19-6.65\end{array}$} \\
\hline
\end{tabular}

${ }^{a}$ Evaluated using two-tailed $\chi^{2}$.

$\mathrm{hm}=$ homozygous; $\mathrm{ht}=$ heterozygous; $\mathrm{wt}=$ wild type; $\mathrm{OR}=$ odds ratio $\mathrm{CI}=$ confidence interval. 
predisposition to develop a strong inflammatory response against the microorganisms capable of activating the MBL molecule.

Franco Ameglio, $M D^{1}$ Giovanni Vento, $M D^{3}$

Costantino Romagnoli, $\mathrm{MD}^{3}$ Bruno Giardina, $\mathrm{PhD}^{1,2}$ Ettore Capoluongo, $\mathrm{PhD}^{1,2}$

${ }^{1}$ Institute of Biochemistry \& Clinical Biochemistry and ${ }^{2}$ International Scientific Institute "Paolo VI;" ${ }^{3}$ Department of Pediatrics, Division of Neonatology, the Catholic University of the Sacred Heart, Rome, Italy

\section{References}

1. Bodamer OA, Mitterer G, Maurer W, Pollak A, et al. Evidence for an association between mannose-binding lectin 2 (MBL2) gene polymorphisms and pre-term birth. Genet Med 2006;8:518-524.

2. Frakking FN, Brouwer N, Zweers D, Merkus MP, et al. High prevalence of mannosebinding lectin (MBL) deficiency in premature neonates. Clin Exp Immunol 2006;145: $5-12$.

3. Verdu P, Barreiro LB, Patin E, Gessain A, et al. Evolutionary insights into the high worldwide prevalence of MBL2 deficiency alleles. Hum Mol Genet 2006;15:2650-2658.

\section{Situs inversus totalis, renal and pancreatic dysplasia, and cysts as an autosomal recessive new entity?}

\section{To the Editor:}

The letter "Atrioventricular canal defect in Bardet-Biedl syndrome: Clinical evidence supporting the link between atrioventricular canal defect and polydactyly syndromes with ciliary dysfunction" ${ }^{1}$ presents a summary of "syndromes associating atrioventricular canal defect (AVCD) and postaxial polydactyly" in Table 1 .

The authors stated, "dextrocardia in the setting of situs inversus has been described in Meckel syndrome and Meckellike syndrome." To support this statement, the authors cited our article. ${ }^{2}$ However, we would like to point out that in this study $^{2}$ and in our previous related study, ${ }^{3}$ the features described did not include polydactyly. This syndrome is therefore not a "Meckel-like syndrome."

The syndrome we described ${ }^{2,3}$ is autosomal recessive and is characterized by situs inversus totalis, polycystic kidney and pancreas, oligohydramnios, and bowing of the lower extremities. Furthermore, the syndrome is distinct from Ivemark syndrome because there were no hepatic cysts.

Sevim Balci, MD

Department of Clinical Genetics

Hacettepe University

Ihsan Dogramaci Children's Hospital

Ankara, Turkey

\section{References}

1. Digilio MC, Dallapiccola M, Marino B.Atrioventricular canal defect in Bardet-Biedl syndrome: Clinical evidence supporting the link between atrioventricular canal defect and polydactyly syndromes with ciliary dysfunction [letter]. Genetics Med 2006; 8:536-537.

2. Balci S, Bostanoglu S, Altinok G, Ozaltin F. Three sibs diagnosed prenatally with situs inversus totalis, renal and pancreatic dysplasia and cysts. Am J Genet Med 2000;90:185-187.

3. Balci S, Bostanoglu S, Altinok G, Ozaltin F. Sibs diagnosed prenatally with situs inversus totalis, renal and pancreatic dysplasia, and cysts: a new syndrome. Am J Genet Med 1999;82:166-169.

\section{Reply to letter from Sevim Balci:}

I agree with Dr. Balci that the patients described in their article cannot be considered affected by "classic Meckel syndrome." Nevertheless, I believe that three elements must be considered when evaluating patients without a definitive diagnosis: (1) the possible great variability in clinical expression of genetic conditions; (2) the high rate of overlapping features, particularly those seen in syndromes with polydactyly; (3) in this specific case, pancreatic and renal cysts are effectively major signs of Meckel syndrome.

Thus, the denomination "Meckel-like" syndrome for these patients, in the absence of an alternative diagnosis, could be, in my opinion, appropriate.

M. Cristina Digilio, MD Medical Genetics

Bambino Gesù Hospital

Piazza S. Onofrio 4, 00165

Rome, Italy 